IZA DP No. 4203

Estimating the Veteran Effect with Endogenous

Schooling When Instruments Are Potentially Weak

Saraswata Chaudhuri

Elaina Rose

June 2009 


\title{
Estimating the Veteran Effect with Endogenous Schooling When Instruments Are Potentially Weak
}

\author{
Saraswata Chaudhuri \\ University of North Carolina at Chapel Hill \\ Elaina Rose \\ University of Washington \\ and IZA
}

Discussion Paper No. 4203

June 2009

IZA

P.O. Box 7240

53072 Bonn

Germany

Phone: +49-228-3894-0

Fax: +49-228-3894-180

E-mail: iza@iza.org

\begin{abstract}
Any opinions expressed here are those of the author(s) and not those of IZA. Research published in this series may include views on policy, but the institute itself takes no institutional policy positions.

The Institute for the Study of Labor (IZA) in Bonn is a local and virtual international research center and a place of communication between science, politics and business. IZA is an independent nonprofit organization supported by Deutsche Post Foundation. The center is associated with the University of Bonn and offers a stimulating research environment through its international network, workshops and conferences, data service, project support, research visits and doctoral program. IZA engages in (i) original and internationally competitive research in all fields of labor economics, (ii) development of policy concepts, and (iii) dissemination of research results and concepts to the interested public.
\end{abstract}

IZA Discussion Papers often represent preliminary work and are circulated to encourage discussion. Citation of such a paper should account for its provisional character. A revised version may be available directly from the author. 
IZA Discussion Paper No. 4203

June 2009

\section{ABSTRACT \\ Estimating the Veteran Effect with Endogenous Schooling When Instruments Are Potentially Weak}

Instrumental variables estimates of the effect of military service on subsequent civilian earnings either omit schooling or treat it as exogenous. In a more general setting that also allows for the treatment of schooling as endogenous, we estimate the veteran effect for men who were born between 1944 and 1952 and thus reached draft age during the Vietnam era. We apply a variety of state-of-the-art econometric techniques to gauge the sensitivity of the estimates to the treatment of schooling. We find a significant veteran penalty.

JEL Classification: $\quad$ C2, J24

Keywords: veteran effect, weak instruments

Corresponding author:

Elaina Rose

Department of Economics

Mail Code 353330

University of Washington

Seattle, WA 98195

USA

E-mail: erose@u.washington.edu 


\section{Introduction}

The costs of war include veterans' foregone civilian human capital and labor market experience as well as the health effects due to exposure to combat (Oi, 1967; Stiglitz and Bilmes, 2008). Estimates of the effect of military service on subsequent civilian earnings vary widely, ranging from negative 10 percent to positive 25 percent. A central issue in the literature is the endogeneity of military service. Young men choose whether or not to volunteer. Even during the Vietnam era that we study, many young men availed themselves of a variety of opportunities to avoid the draft.

Instrumental variables (IV) can correct for the endogeneity-bias in the estimates of veteran effect. The challenge is finding an instrument for military service. Angrist $(1989,1990,1991)$ and Angrist and Chen (2008) show that the randomization of the Vietnam era draft provides a suitable instrument.

A second issue is the treatment of schooling. Most models of the veteran effect either omit schooling or treat it as exogenous. Rosenzweig and Wolpin (2000) point out that the interpretation of the estimates depends on whether schooling as well as veteran status are endogenous with respect to the lottery. The objective of this paper is to treat schooling as well as military service as endogenous and gauge the sensitivity of the estimates to alternative treatments of schooling commonly found in the literature. Following Card (1995) we use the presence of four-year accredited public and private colleges in the vicinity of the respondent's residence as instruments for schooling.

Our sample from the National Longitudinal Survey of Youth (NLSY) is smaller than the Census samples used in recent IV work. This reduces the precision of the estimates. The issue is compounded by the fact that our close attention towards the exogeneity of instruments also led to the 
choice of instruments that are only weakly correlated with the endogenous regressors and thus reducing the precision of the estimates further. Nevertheless, we are still able to conclude that the veteran effect is negative. The effect is even more negative once we control for the individual's schooling and focus on the veteran effect net of schooling.

To help address the concern of misleading inference from the standard procedures due to the presence of the "weak instruments", we apply various weak instrument robust methods of inference and support our conclusions. We use only the plug-in-based robust methods of inference on subsets of structural coefficients (associated with the endogenous regressors) because these methods are more powerful than their projection-based counterparts. The plug-in-based methods were recently proposed by Stock and Wright (2000) and Kleibergen (2004, 2005), and are still not routinely used by applied researchers. ${ }^{3}$ A secondary objective of the present paper is to demonstrate the usefulness of these methods to validate conclusions from the standard procedures, if not use them as standards.

The rest of the paper is organized as follows. Section II provides background on the literature on the veteran effect and returns to schooling. Section III outlines the empirical analysis. The data are described in Section IV, and Section V presents the results. Section VI concludes.

\section{Background}

\section{The Veteran Effect: Premium or Penalty?}

It is unclear a priori whether military service increases or decreases earnings. On one hand, there are opportunities for human capital acquisition, which, for many, would not otherwise be

\footnotetext{
${ }^{3}$ Kleibergen (2007) and Kleibergen and Mavroeidis (2008a) prove that these methods do not ever over-reject the true value of the structural coefficients. To the best of our knowledge, these methods have, since then, found applications only in the literature on the new Keynesian Phillips curve (see, for example, Kleibergen and Mavroeidis, $2008 \mathrm{~b})$.
} 
available. The military provides on-the-job training and college education is subsidized in-service and within service, and post-service through GI Bills. ${ }^{4}$

Servicemen gain less measureable forms of human capital as well. For instance, the military serves as a "bridging environment" in which youths from disadvantaged backgrounds can learn lessobservable skills such as an ability to function in a structured environment (Teachman and Call, 1996). Successful completion of a term of service signals favorable pre-market ability and acquired unobservable skills (DeTray, 1982). Taken together, these factors suggest that veterans will receive a premium when they return to the civilian sector.

Yet military service entails costs as well as benefits. Draftees are drawn off their otherwise optimal human capital investment paths. So are young men who enlist in order to preempt being drafted into the infantry and those enlisting for non-financial motives such as patriotism or family tradition. Soldiers exposed to combat experience adverse physical and mental consequences. It is unclear whether, on net, military service increases or decreases earnings.

Estimates of the effect of military service vary by factors such as age, era, and approach to estimation. Early estimates are based on Ordinary Least Squares (OLS). Rosen and Taubman (1982) suggest a premium of 10 percent for World War II veterans and a penalty of 19 percent for Vietnam era veterans. There appears to be no effect of military service on the earnings of Korean War veterans (Schwartz, 1986). Other OLS-type studies report estimates that vary by service, rank and military occupational specialty. Air force veterans tend to earn more than veterans of other services (MacLean and Elder, 2007). Officers tend to fare better than enlisted personnel (MacLean, 2008). Technical skills transfer more readily to the civilian sector (Bryant and Wilhite, 1990; Goldberg and Warner, 1987). Blacks achieve greater premia and suffer smaller penalties than

\footnotetext{
${ }^{4}$ Rostker (2006) outlines programs available from 1973 to 2004 . New programs continue to be introduced. The best references on current offerings are the services' recruiting web pages.
} 
whites (Bryant, Samaranayake and Wilhite, 1993; Teachman and Tedrow, 2004. Costs of service are greatest for draftees and soldiers exposed to combat (Teachman, 2004; MacLean and Elder 2007).

Estimating the effect of military service on earnings poses an empirical challenge. As Rosen and Taubman note, military service is endogenous. The direction of the bias in the OLS estimate is ambiguous. On one hand, youths with better opportunities in the civilian sector will tend to opt out of the military. On the other hand, those with sufficiently low physical or cognitive ability will not qualify. Another source of endogeneity is the measurement error in veteran status, and this tends to bias the OLS estimates towards zero.

Instrumental variables estimates allow researchers to overcome the problem of endogeneity and obtain causal estimates of the veteran effect. Several studies exploit the randomness of draft lotteries as a valid instrument. Angrist and Krueger (1994) report premia ranging from 6 to 25 percent for World War II veterans. Angrist $(1989,1990)$ finds a Vietnam era penalty of 15 percent for whites, but no effect for blacks. These studies suggest that OLS estimates of the gains from service during World War II and the losses due to service during the Vietnam era are both biased away from zero. Angrist and Chen (2008) estimate long-run effects by capturing Vietnam era youths until 2000. They find that the Vietnam veteran penalty dissipates as men approach the overtaking point, where earnings profiles flatten (Mincer 1974).

Military Service and Schooling:

The interpretation of all these estimates hinges on the treatment of schooling in the estimating equation. There is an extensive literature on the returns to schooling emphasizing the fact that schooling is endogenous with respect to unobserved ability (see Card, 1999 for a survey). Those with more favorable labor market unobservables obtain more schooling, leading to an upward 
bias in the OLS estimates of the returns to schooling. On the other hand, measurement error in schooling will bias estimates downward. A variety of IV approaches have been used to generate (asymptotically) unbiased estimates. The literature generally reports IV estimates exceeding comparable OLS estimates. There are several reasons to think that military service is related to schooling. First, the college tuition subsidies provide an incentive for continued schooling. Second, during the Vietnam era, potential draftees could defer their obligations by remaining in school. Card and Lemieux (2001) show that young men reaching draft age at the height of the draft were more likely to remain in college. Third, those with disabilities may be less capable of returning to school, and finally, the unconstrained optimal level of schooling may exceed the optimal level subject to the constraint of service or draft eligibility. Angrist and Chen's (2008) Vietnam era veteran premium several decades beyond the military service is attributable to the additional education subsidized by the GI Bill.

The joint endogeneity of schooling and military service has implications for the estimates of the veteran effect. When both are treated as exogenous, OLS estimates will be biased. When both are treated as endogenous, IV estimates with sufficiently large samples and appropriate instruments will be unbiased. When only veteran status is treated as endogenous, and schooling and veteran status are correlated, bias in the estimate of the returns to schooling can spread to the estimate of the veteran effect (Rosenzweig and Wolpin, 2000). When schooling is omitted, the veteran effect is interpreted as gross of the effect of military service on schooling.

Our approach allows us to assess the sensitivity of estimates of the veteran effect to alternative treatments of schooling. As in Angrist (1989), we use data from the National Longitudinal Survey of Young Men (NLS-YM) of men who were draft age during the Vietnam era. Our instrumental variables can be broadly classified under two categories - (i) variables describing 
the draft eligibility of respondents and (ii) variables indicating the presence of an accredited four years college in the vicinity of the respondents' residence. Angrist $(1989,1990)$ and Angrist and Chen (2008) instrument for military service with draft lottery parameters. Card (1995), using the NLS-YM, instruments for schooling with presence of college. Our sample is small relative to recent IV studies of the veteran effect and returns to schooling and estimates and specification tests can be sensitive to the presence of weak instruments. Therefore, we apply a variety of state-of-the-art approaches to gauge the properties of the instrumental variables estimators.

\section{Estimation}

\section{Empirical Model:}

We consider the following model to estimate the net effect of a man's veteran status on his wage in the civilian market (later in his life cycle), after controlling for his years of schooling and other background characteristics. Let

$$
w_{i}=V_{i} \gamma+S_{i} \beta+X_{i} \theta+\xi_{i}
$$

where $w_{i}$ is the logarithm of the real wage for the $\mathrm{i}$-th man in the civilian labor market, $V_{i}(=1)$ is a dummy variable indicating whether he ever served in the military, $S_{i}$ is his years of schooling, and $X_{i}$ contains an intercept term and a set of background variables including his demographic, household and locational characteristics. The error term $\xi_{i}$ includes the unobservable human capital and the ability of the i-th man.

We are primarily interested in the coefficient $\gamma$. For small values of $\gamma$, this coefficient measures the net percent change in real wage attributable to veteran status, after controlling for years of schooling and other background characteristics. However, as pointed out by Halverson and Palmquist (1981), for not so small values of $\gamma$ the appropriate measure should be $\delta=\left(e^{\gamma}-1\right)$. 
Our estimates for $\gamma$ are not small and hence we also report estimates for $\delta$. The coefficient $\beta$ measures the net returns to schooling, after controlling for the veteran status and other background characteristics, and is interesting in its own right.

The main challenges in conducting inference on $\gamma$ are the endogeneity of $V_{i}$ and $S_{i}$ and the possible non-zero correlation between them. In Section II we discussed why $V_{i}, S_{i}$ and $\xi_{i}$ are potentially mutually correlated. The return to schooling literature suggests that schooling is positively correlated with unobserved characteristics that affect wages positively. At the same time, evidence of measurement error in schooling data is common in the literature.

The correlation between schooling and veteran status is also ambiguous a priori. In our sample, empirically, veterans have slightly more schooling than the non veterans. A closer look reveals that of the 1080 veterans included in our sample, more than 61.5 percent went for additional schooling since their first (or only) term with the armed forces; and on average they got about 1.32 additional years of schooling. While it does not necessarily establish a causal effect of one's veteran status on schooling, this certainly calls for a thorough inspection of the treatment of schooling in the specification described by (1). We address this issue further in Section V while discussing our results.

\section{Evaluating the Instrumental Variables Estimates:}

Likely endogeneity of veteran status and schooling and evidence of correlation between these variables suggest that simple OLS methods cannot consistently estimate the net effect of veteran status. IV is the most common method of inference in these situations. A necessary condition for consistency of the IV estimators is that the instruments used for the two endogenous regressors are exogenous which, in turn, implies that the variation induced by the instruments in the endogenous regressors is uncorrelated with the unobserved structural error $\xi$. Unfortunately, it is not possible to 
test exogeneity of the instruments without the prior assumption that the model is overidentified, i.e., there are at least three instruments, and at least two independent linear combinations of these instruments are exogenous. We try to overcome this limitation of the test of exogeneity of the instruments by considering various alternative specifications while testing exogeneity (reported in Table 3 of the appendix and discussed in Section V).

However, the close attention to exogeneity also leads us to be conservative in the choice of instruments and restricts us from capturing some variations in the endogenous explanatory variables veteran status and schooling. Ideally asymptotic efficiency of the inference should be the only virtue at stake here. However, as Bound, Jaeger and Baker (1995) emphasize, this could also give rise to the so-called "weak instrument problems" in the usual asymptotic methods of inference based on the two-stage least squares (TSLS) framework. In such cases, TSLS estimates can be inconsistent and asymptotically biased, and the usual t-test and F-test tend to over-reject the true value of the parameters. These problems do not go away even with relatively large sample size. Hence, given the small number of observations in our sample, such problems are likely to be a major concern. ${ }^{5}$

To overcome such problems we also consider the recently proposed "weak instrument robust" methods of inference. The broader aspects of our conclusion remain unchanged. The weak instrument robust methods provide a way for testing the parameters of interest, and then subsequently inverting the tests to obtain confidence regions for the parameters. Unlike the usual ttest and F-test, these tests are not over-sized even in finite samples (as long as the instruments are exogenous) and hence the asymptotic coverage probability of the corresponding confidence regions

\footnotetext{
${ }^{5}$ It is important to distinguish between the two types of problems that can arise due to weak instruments. The first problem is a reduction in precision; this is natural because the data do not contain enough information to precisely identify the parameters in the model. The second problem is the so-called "weak instrument problem" and this refers to the case where the conventional first-order asymptotic results provide poor approximation to the finite sample behavior of the estimators and tests; namely, the usual estimates tend to precisely report wrong values of the parameters and the usual tests tend to over-reject the true value of the parameters. Weak instrument robust methods were developed to address the second problem and overcome such misleadingly spurious precision in the usual methods of inference.
} 
does not exceed their nominal counterparts. We use the subset AR test, the subset $\mathrm{K}$ test and the subset KJ test (see, for example, Kleibergen, 2004, 2007; Kleibergen and Mavroeidis, 2008a) to deal with the potential problem of weak instruments. These methods are based on the plug-in principle and are more powerful than their projection-based counterparts (see Chaudhuri, 2008). Although these methods can be conservative in finite samples; unlike the conventional methods, they do not, however, report incorrect parameter values with spuriously high precision or over-reject the true parameter value in the presence of weak instruments.

\section{Estimation Framework:}

We use the generalized method of moments (GMM) to infer on the parameters $\gamma$ and $\beta$ in (1). The moment restrictions for the inference are based on the following four instruments - (i) the lottery number assigned to the young man based on his date of birth, (ii) the lottery ceiling for the year when this young man attained draft age, (iii) a dummy variable indicating the presence of a four year accredited public college and (ii) a dummy variable indicating the presence of a four year accredited private college in the neighborhood of the young man's residence in 1966. Denoting these four instruments generically by $\bar{Z}_{i}$ and letting $Z_{i}=\left[\bar{Z}_{i}, X_{i}\right]$, the assumption of exogeneity of the instruments and the background variables gives the moment restrictions (at the true value of the parameters)

$$
E\left[Z_{i}^{\prime}\left(w_{i}-V_{i} \gamma-S_{i} \beta-X_{i} \theta\right)\right]=0 \text { for all } i=1, \ldots, n
$$

We report the results of inference from the usual two-stage least squares methods based on the moment restrictions in (2). We also report the results of weak instrument robust inference from the Continuous Updating GMM based on the same set of moment restrictions. The results are discussed in Section V. 


\section{Data}

We use data from the National Longitudinal Survey of Young Men (NLS-YM) to estimate the parameters in (1). The NLS-YM is a nationally representative data set of young men aged 14-24 in 1966. Respondents were followed annually until 1971, and then annually or biennially until 1981.

Men born between 1944 and 1952, who constitute about 82 percent of the entire sample, were subject to the annual lotteries from 1969 through 1972. These men are the subject of our study. Veteran status is captured in two ways. First, there are a number of specific questions about military service. Second, the data indicate whether a respondent was unavailable because he was currently serving in the military. Schooling is measured as the highest grade completed reported on the survey.

The dependent variable, real hourly earnings, is measured in 1981 dollars at the oldest age at which the respondent appeared on the survey. In order to capture the effect of veteran status (and schooling) as late as possible in the man's life-cycle, we further restrict our attention to men whose last recorded wage was earned at the age of 29 or more. ${ }^{6}$ Ignoring the 1.69 percent respondents with missing wage figures, 65.75 percent of men interviewed in the survey earned their last wage at age 29 or more. $^{7}$ Lastly we ignore one respondent with an implausible birthday (04/31/1949) and three respondents with missing information on the type of area (urbanized, urban place or rural) of the respondent's residence in 1966. Our final sample consists of 2754 respondents.

In all, 1080, or 39 percent of the final sample, were veterans and 1674 were non-veterans. Sample size and reporting issues preclude us from disaggregating by rank, service or military occupation. Highest year of schooling completed was, on average, slightly higher for veterans (13.6) than non-veterans (13.4). However, the partial correlations of veteran status and schooling,

\footnotetext{
${ }^{6}$ Among all the respondents born between 1944 and 1952, the wage figures are missing for 66 men and 6 reported 0 wage.

${ }^{7} 60.39$ percent satisfies the stricter criterion of last recorded wage being earned at age 30 or more.
} 
controlling for the set of regressors used in the analysis is negative. These controls include race, region, ${ }^{8}$ urbanicity ${ }^{9}$ and the age and year at which the wage was earned.

The NLS-YM provides suitable instruments for both veteran status and schooling. Following Angrist (1989, 1990) and Angrist and Chen (2008) we use dimensions of draft status to instrument for military service; in particular we use the lottery number assigned to the individuals born between 1944 and 1952 and we use the ceiling of the draft-lottery announced for the year the individual became draft eligible. Following Card (1999), variables indicating the presence of four year accredited public and private colleges are used to instrument for schooling.

The full set of sample statistics is reported in Table 1.

\section{Results}

In order to illustrate the sensitivity of the results to different treatments of schooling and treatment of potentially endogenous variables we compare five specifications of the relationship described in (1). The results are reported in Table 2. Corresponding results (estimates and standard errors) for the control variables are reported in Table 2(a).

The most general specification includes both schooling and veteran status and treats both as endogenous. The IV results, reported in column (A), indicate a large veteran penalty. The coefficient $\gamma$ of -.374 corresponds to a veteran effect of -31.2 percent $\left(\delta=\mathrm{e}^{\gamma}-1\right)$. The standard error of this estimate is rather large, around 15 percent (obtained by the Delta method); and a 95 percent confidence region suggests that the wage reduction for veterans can vary from 1 percent to 61 percent. Nevertheless, we can safely reject that the net veteran premium is zero (or positive).

\footnotetext{
${ }^{8}$ The regions are northeast, mid-atlantic, east north central, west north central/mountain, east south central, west south central, pacific; and south atlantic as a default.

${ }^{9}$ The area is categorized as urbanized if its population is more than 125,000 , as an urban place if the population is between 12,000 and 125,000, and rural otherwise.
} 
The estimate of the returns to schooling of 16.1 percent ( $\mathrm{p}$-value $=.078$ ) is comparable to Card's (1995).

We find that both veteran status and schooling are endogenous ( $\mathrm{p}$-value $=.031$ for veteran status alone, .082 for schooling alone, and .055 for veteran status and schooling jointly). The test is based on a C-statistic defined as the difference of two Sargan-Hansen statistics: one for the regression treating the suspected regressor(s) as exogenous, and the other treating it (them) as endogenous.

Military service impacts earnings both directly, through, say, skill acquisition and indirectly through its association with schooling. The estimate of the veteran effect from column (A) is interpreted as the direct effect of military service, net of the indirect effect through schooling. In specification (B) we omit schooling to obtain an estimate of the gross veteran effect. This estimate captures the direct effect as well as the indirect effect operating through schooling, for instance through the GI bill which is available only to veterans.

The estimate of the gross veteran effect -15.8 percent $(\mathrm{p}$-value $=.14)$ is greater than the estimate of the net effect, consistent with the case in which the returns to schooling are positive and schooling and veteran status are positively correlated. Although the standard errors of the veteran effect are similar in the two specifications, because the point estimate of the gross effect is closer to zero we cannot reject that the gross effect is different from zero. In this specification, we are also unable to reject the hypothesis that veteran status is exogenous $(\mathrm{p}$-value $=.244)$.

Specifications (C) and (D) are the OLS analogs to specifications (A) and (B). We would expect that, for the Vietnam era, veteran status will be negatively correlated with the earnings equation unobservables, biasing the OLS estimate downward. We would also expect the returns to schooling to be positively correlated with those unobservables, biasing the OLS coefficient upward. 
Instead, we find the opposite: The OLS estimate of the veteran effect is greater (i.e., more positive) than the IV estimate and the OLS estimate of the returns to schooling is smaller than the IV estimate. The estimate of the returns to schooling when schooling is treated as exogenous in Specifications (C) and $(\mathrm{E})$ is 4.9 percent (p-value $=.003)$ and is about 1.5 percentage points lower than Card's (1995).

The endogeneity tests indicate that both schooling and veteran status are endogenous. But are the OLS estimates significantly different from the IV estimates? In terms of Specification (A), estimate of the net effect, the IV estimates indicate that both schooling and veteran status are endogenous. However, using the Hausman test we cannot reject that the difference between the probability limits of the IV and OLS estimates are significant $(\mathrm{p}$-value $=.158) .{ }^{10}$ In other words, while the endogeneity tests indicate that OLS is misspecified we cannot say whether the misspecification is sufficient to generate a "significant" asymptotic bias. Of course, this may be due to lack of precision.

Many studies of the veteran effect control for schooling but do not have data to instrument for it. Specification (E) is that model. The point estimate of the veteran effect, - 20.9 percent, lies between the IV estimates of the gross and net effect of veteran status. The estimate lacks precision and is not statistically significant. Again, although the test of endogeneity indicates that model (E) is misspecficied our estimates are not sufficiently precise to reject no misspecification-bias of the OLS estimate $(\mathrm{p}$-value $=0.34)$.

Are these results impacted by weak instrument issues?

Yes. The first stage F-statistics for testing the relevance of the (excluded) instruments are low: 8.46 for veteran status and 2.53 for schooling. The partial $R^{2}$ statistics are .012 and .004 respectively for the two endogenous regressors (see Shea, 1997). Hence there is evidence that the

\footnotetext{
${ }^{10}$ To see if the conclusion from the Hausman test is affected by the presence of weak instruments, we use all three forms of the statistic described in equation 3.9 (page 568) of Staiger and Stock (1997). The conclusion does not change with the other forms of the Durbin-Wu-Hausman statistic.
} 
instruments do not explain much variation of the endogenous regressors, especially schooling. ${ }^{11} \mathrm{~A}$ more systematic test for weak instruments is the test proposed by Stock and Yogo (2005). This test suggests that given our model and the exogenous instruments, the maximum (asymptotic) bias of the TSLS estimators of $\gamma$ and $\beta$, relative to their OLS estimators is more than 30 percent. If the instruments were strongly correlated with the endogenous regressors, one would expect this to be close to 0 . The test by Stock and Yogo also suggests that the nominal size of 5 percent Wald test for jointly testing the significance of veteran status and schooling is likely to be more than 25 percent. Again, if the instruments were strongly correlated with the endogenous regressors, this would be close to 5 percent.

To gauge how seriously these problems affect our overall results, we followed the recently proposed weak-instrument-robust methods of inference. These methods are valid as long as the instruments are exogenous.

Are the instruments exogenous?

It is reassuring to observe that the over-identification test cannot reject the exogeneity of the instruments even at 97 percent level. This should be hardly surprising since we ended up with weak instruments in the first place because we were too careful to ensure the exogeneity of the instruments. More information on the Sargan-Hansen C-test for testing exogeneity of the individual instruments under various instrument specifications is provided in Table 3.

We can also justify the exogeneity of the instruments intuitively. The lottery number assigned to each man was based on his date of birth and hence can be argued to be uncorrelated with unobserved individual characteristics (see Angrist, 1989). Similarly one could argue that the lottery ceiling for the draft years were also determined independently of the individuals unobserved characteristics. It is, however, less straightforward to intuitively justify the exogeneity of the other

\footnotetext{
${ }^{11}$ The Anderson LM statistic, however, rejects the hypothesis of under-identification in the model at 5.5 percent level.
} 
instruments, based on the presence of four year accredited colleges in the vicinity of the respondent's residence in 1966 (see Card, 1995 for an elaborate discussion). Nevertheless, given that the exogeneity of lottery number and lottery ceiling is more convincing, in Table 3 we have tested the exogeneity of the variables indicating the presence of colleges (individually and jointly) under the assumption that the variables involving lottery are exogenous. The minimum p-value for the over-identification test is 84 percent; and for the specification (A), that we actually use, the pvalue is more than 97 percent. Hence, we can strongly argue that the instruments used in the IV regression are exogenous. ${ }^{12}$

\section{Results from weak-instrument-robust methods of inference:}

Weak-instrument robust methods - the subset AR test and the subset K test are used to test different hypothesized values of the parameters $\gamma$ and $\beta$. These tests are inverted to obtain confidence regions for the parameters. The confidence regions are the collection of hypothesized values of the parameters that cannot be rejected by the weak instrument robust tests. Due to presence of weak instruments, these confidence regions are very wide (given a set of instruments, this problem is unavoidable). In fact, the regions obtained by inverting the subset AR test are unbounded. The regions obtained by inverting the subset $\mathrm{K}$ test are considerably more precise than those obtained from the subset AR test. However, as pointed out by Kleibergen (2004), the confidence regions based on the $\mathrm{K}$ test can spuriously contain non-representative value due to a peculiarity in the properties of the K statistic. Methods to deal with this unintuitive (and unhelpful) property of the K test have been suggested in the literature (see Kleibergen, 2004, 2007; Kleibergen and Mavroeidis, 2008a, 2008b; Chaudhuri, 2008). One such method, the subset KJ test, is also used to obtain

\footnotetext{
${ }^{12}$ We also use the $H_{3}$ (for columns 1 and 2 of Table 3) and the $H_{4}$ statistics (for all the columns) described in Hahn, Ham and Moon (2008) to test for exogeneity of the instruments. The p-value for all these tests exceeds 95 percent and hence strongly supports the exogeneity hypothesis. The results are not reported here because the weighting matrix of the quadratic form is near-singular in all cases and there may be some concern with the ill-conditioned computations.
} 
confidence regions in Figure 1 (and 1(b)); and the following discussion is based on these regions. (All the confidence regions based on these weak instrument robust methods are plotted in Figure 1.)

A 95 percent confidence region for $\gamma$ can vary from -1 percent to -121 percent, and hence the net veteran effect can vary from a wage reduction of 1 percent to 70 percent (obtained by projection). Of course, this is very imprecise. However, it is also interesting to note that, even with such degree of imprecision, we can reject a zero or positive net effect of veteran status. A 95 percent confidence region for $\beta$ shows that the increase in wage due to an additional year of schooling can vary from 3.5 percent to 54.5 percent.

It is also reassuring to note that the TSLS estimates (that are not supposed to be robust to weak instruments) are also included inside these robust confidence regions, showing that our main results based on TSLS are not terribly misleading in this context.

\section{Conclusion}

Estimates of the effect of military service vary by era, age and methodology. We focus on the third issue using a sample of relatively young veterans of the Vietnam era. Two methodological issues are the joint endogeneity of both military service and schooling, and the potential weakness of the instruments. The sample size $(\mathrm{N}=2754)$ is also relatively small for microeconometric research and results in lower precision than we would like.

Point estimates suggest a veteran penalty of about 20.9 percent when schooling is treated as exogenous and 31.2 percent when schooling is treated as endogenous. OLS estimates are positive and small. The IV estimate of the effect of military service, gross of schooling, is -15.8 percent. Rosenzwieg and Wolpin's (2000) point that schooling is endogenous is validated; but, in our sample, it does not seem to cause a "statistically significant" bias in the estimate of veteran effect. 
Still, our result has a substantive implication. Approximately 9-10 years after Vietnam era service, veterans suffer significant penalty.

The exercise is the first application of many new techniques for evaluating properties of instrumental variables estimators and dealing with weak instruments. The focus on a model with two endogenous variables and the use of a cross-section microeconometric data set are also novel. We hope this paper will provide a guide for other researchers applying the state-of-the art approaches to instrumental variables models. 


\section{$\underline{\text { References }}$}

Angrist, J. (1989). "Using the Draft Lottery to Measure the Effects of Military Service on Civilian Earning." Research in Labor Economics, 10, edited by Ronald Ehrenberg. Greenwich, CT, JAI.

Angrist, J. (1990) "Lifetime Earnings and the Vietnam Era Draft Lottery: Evidence from Social Security Administrative Records.” American Economic Review, 80, 313-336.

Angrist, J. (1991). "The Draft Lottery and Voluntary Enlistment in the Vietnam Era." Journal of the American Statistical Association, 86, 584 - 595.

Angrist, J. and A. B. Krueger (1991). "Does Compulsory School Attendance Affect Schooling and Earnings?” The Quarterly Journal of Economics, 106, 979 - 1014.

Angrist, J. (1993). "The Effect of Veteran Benefits on Education and Earnings." Industrial and Labor Relations Review, 46, 637 - 652.

Angrist, J. and A. Krueger (1994). "Why Do World War II Veterans Earn More than Nonveterans?" Journal of Labor Economics, 12, 74 - 97.

Angrist, J. and S. Chen (2008), "Long-Term Economic Consequences of Vietnam-Era Conscription: Schooling, Experience and Earnings.” IZA DP No. 3628.

Bound, J., D. A. Jaeger, and R. M. Baker (1995). "Problems with Instrumental Variables Estimation when the Correlation Between the Instruments and the Endogenous Explanatory Variable is Weak." Journal of the American Statistical Association, 90, 443 - 450.

Bryant, R. and A. Wilhite (1990) "Military Experience and Training Effects on Civilian Wages." Applied Economics, 22, 69-81.

Bryant, R., V. Samaranayake and A. Wilhite (1993) "The Effect of Military Service on the Subsequent Civilian Earnings of the post-Vietnam Veteran. Quarterly Review of Economics and Finance, 33, 15-31.

Card, D. (1995): "Using Geographical Variation in College Proximity to Estimate the Return to Schooling." Aspects of Labour Market Behavior: Essays in Honor of John Vanderkamp, edited by Christofides, L. N., E. K. Grant and R. Swidinsky. Toronto: University of Toronto Press.

Card, D. (1999) “The Causal Effect of Education on Earnings." Handbook of Labor Economics, 3, edited by Orley Ashenfelter and David Card. Amsterdam: Elsevier.

Card, D. and T. Lemeiux (2001) "Draft Avoidance and College Attendance: The Unintended Legacy of the Vietnam War" American Economic Review Papers and Proceedings 91, 97-107.

Chaudhuri, S. (2008). "Testing of Hypotheses for Subsets of Parameters." Technical report, Department of Economics, University of Washington. 
De Tray, D (1982) "Veteran Status as a Screening Device." American Economic Review, 72, 133142.

Goldberg, M. and J. Warner (1987) "Military Experience, Cevilian Experience and the Earnings of Veterans.” Journal of Human Resources, 22, 62-81.

Hahn, J., J. Ham and H. R. Moon (2008). “The Hausman Test and Weak Instruments.” Technical report, Department of Economics, University of California and University of Southern California.

Halvorsen, R. and R. Palmquist (1980). "The Interpretation of Dummy Variables in Semilogarithmic Equations." American Economic Review, 70, 474 -475.

Kleibergen, F. (2004). "Testing Subsets of Parameters in the Instrumental Variables Regression Model." The Review of Economics and Statistics, 86, 418 - 423.

Kleibergen, F. (2005). "Testing Parameters In GMM Without Assuming That They Are Identified." Econometrica, 73, 1103 - 1123.

Kleibergen, F. (2007). "Subset Statistic in the Linear IV Regression Model.” Technical Report, Department of Economics, Brown University.

Kleibergen, F. and S. Mavroeidis (2008a). "Inference on subsets of parameters in GMM without assuming identification." Technical report, Department of Economics, Brown University.

Kleibergen, F. and S. Mavroeidis (2008b). "Weak Instrument Robust Tests in GMM and the New Keynesian Phillips Curve.” Technical report, Department of Economics, Brown University.

MacLean, A. and G. Elder (2007) "Military Service in the Life Course." Annual Review of Sociology 33, 175-196.

MacLean, A. (2008) "The Privileges of Rank: The Peacetime Drat and Later-life Attainment." Armed Forces and Society 34, 682-713.

Mincer, J. (1993) Schooling, Experience and Earnings, Ashgate.

Oi, Walter (1967) “The Economic Cost of the Draft," American Economic Review 67(2), 39-62.

Rosen, S. and P. Taubman (1982). "Changes in Life-Cycle Earnings: What Do Social Security Data Show?" The Journal of Human Resources, 17, 321 - 338.

Rosenzweig, M. R. and K. L. Wolpin (2000). "Natural "Natural Experiments" in Economic." Journal of Economic Literature, (38:4), 827 - 874.

Rostker, B. (2006). "I Want You: The Evolution of the All-Volunteer Force”. RAND Corporation. 
Schwartz, S. (1986) "The Relative Earnings of Vietnam and Korean-Era Veterans." Industrial and Labor Relations Review, 39, 564-572.

Shea, J. (1997). "Instrument Relevance in Multivariate Linear Models: A Simple Measure." The Review of Economics and Statistics, 79, 348 - 352.

Staiger, D. and J. H. Stock (1997). "Instrumental Variables Regression with Weak Instruments." Econometrica, 65, 557 - 586.

Stiglitz, Joseph and Linda Bilmes (2008) The Three Trillion Dollars War, W.W. Norton \& Co.

Stock, J. H. and J. H. Wright (2000). "GMM with Weak Identification.” Econometrica, 68. 1055 1096.

Stock, J. H. and M. Yogo (2005). "Testing for Weak Instruments in Linear IV Regression." Identification and Inference for Econometric Models: Essays in Honor of Thomas Rothenberg, edited by D. W. K. Andrews and J. H. Stock, Cambridge: Cambridge University Press, 80 - 108.

Teachman, J and V. Call (1996) "The Effect of Military Service on Educational, Occupational and Income Attainment." Social Science Research, 25, 1-31.

Teachman, J. and L.M. Tedrow (2004). "Wages, Earnings, and Occupational Status: Did World War II Veterans Receive a Premium?" Social Science Research, 33, 581 - 605.

Teachman, J. (2004). "Military Service during the Vietnam Era: Were There Consequences for Subsequent Civilian Earnings?” Social Forces, 83, 709 - 730.

Teachman, J. (2005). "Military Service in the Vietnam Era and Educational Attainment." Sociology of Education, 78, 50 - 68. 
Table 1: Descriptive Statistics

\begin{tabular}{|c|c|c|c|}
\hline \multirow[t]{2}{*}{ Variables } & \multicolumn{3}{|c|}{$\begin{array}{l}\text { Mean } \\
\text { (s.d.) }\end{array}$} \\
\hline & Overall & Veterans & Not Veterans \\
\hline $\log$ (real wage: $1981 \$)$ & $\begin{array}{l}6.734 \\
(.502)\end{array}$ & $\begin{array}{l}6.761 \\
(.476)\end{array}$ & $\begin{array}{l}6.717 \\
(.517)\end{array}$ \\
\hline Veteran (proportion) & $\begin{array}{l}.392 \\
(.488)\end{array}$ & - & - \\
\hline $\begin{array}{l}\text { Schooling: Highest year } \\
\text { completed }\end{array}$ & $\begin{array}{l}13.49 \\
(2.67)\end{array}$ & $\begin{array}{l}13.562 \\
(2.150)\end{array}$ & $\begin{array}{l}13.439 \\
(2.959)\end{array}$ \\
\hline Black & $\begin{array}{c}.252 \\
(.434)\end{array}$ & $\begin{array}{l}.224 \\
(.417)\end{array}$ & $\begin{array}{l}.270 \\
(.444)\end{array}$ \\
\hline \multicolumn{4}{|c|}{ Proportion of men whose wage is from the year: } \\
\hline 1975 & $\begin{array}{l}.020 \\
(.139)\end{array}$ & $\begin{array}{c}.021 \\
(.144)\end{array}$ & $\begin{array}{l}.019 \\
(.135)\end{array}$ \\
\hline 1976 & $\begin{array}{l}.027 \\
(.162)\end{array}$ & $\begin{array}{c}.023 \\
(.150)\end{array}$ & $\begin{array}{c}.029 \\
(.169)\end{array}$ \\
\hline 1978 & $\begin{array}{c}.048 \\
(.214)\end{array}$ & $\begin{array}{l}.053 \\
(.224)\end{array}$ & $\begin{array}{c}.045 \\
(.208)\end{array}$ \\
\hline 1980 & $\begin{array}{l}.088 \\
(.283)\end{array}$ & $\begin{array}{l}.090 \\
(.286)\end{array}$ & $\begin{array}{l}.087 \\
(.281)\end{array}$ \\
\hline 1981 & $\begin{array}{c}.811 \\
(.392)\end{array}$ & $\begin{array}{c}.809 \\
(.393)\end{array}$ & $\begin{array}{c}.812 \\
(.391)\end{array}$ \\
\hline Age at which wage is earned & $\begin{array}{l}32.354 \\
(2.289)\end{array}$ & $\begin{array}{l}32.506 \\
(2.186)\end{array}$ & $\begin{array}{l}32.257 \\
(2.349)\end{array}$ \\
\hline \multicolumn{4}{|c|}{ Residence at the age of 14 (South-Atlantic is omitted category) } \\
\hline Northeast & $\begin{array}{l}.040 \\
(.196)\end{array}$ & $\begin{array}{l}.040 \\
(.196)\end{array}$ & $\begin{array}{l}.040 \\
(.196)\end{array}$ \\
\hline Mid-Atlantic & $\begin{array}{l}.161 \\
(.367)\end{array}$ & $\begin{array}{l}.150 \\
(.357)\end{array}$ & $\begin{array}{l}.168 \\
(.374)\end{array}$ \\
\hline East North Central & $\begin{array}{l}.186 \\
(.389)\end{array}$ & $\begin{array}{l}.191 \\
(.393)\end{array}$ & $\begin{array}{l}.182 \\
(.386)\end{array}$ \\
\hline West North Central & $\begin{array}{l}.095 \\
(.294)\end{array}$ & $\begin{array}{l}.124 \\
(.330)\end{array}$ & $\begin{array}{l}.077 \\
(.268)\end{array}$ \\
\hline East South Central & $\begin{array}{l}.098 \\
(.297)\end{array}$ & $\begin{array}{l}.089 \\
(.285)\end{array}$ & $\begin{array}{l}.104 \\
(.305)\end{array}$ \\
\hline West South Central & $\begin{array}{l}.115 \\
(.319)\end{array}$ & $\begin{array}{l}.101 \\
(.301)\end{array}$ & $\begin{array}{l}.124 \\
(.330)\end{array}$ \\
\hline Pacific & $\begin{array}{c}.089 \\
(.285)\end{array}$ & $\begin{array}{l}.088 \\
(.283)\end{array}$ & $\begin{array}{l}.090 \\
(.286)\end{array}$ \\
\hline
\end{tabular}


Table 1: Descriptive Statistics (continued)

\begin{tabular}{lccc}
\hline \hline Variables & & \multicolumn{1}{l}{$\begin{array}{l}\text { Mean } \\
\text { (s.d.) }\end{array}$} & \\
& Overall & Veterans & Not Veterans \\
\cline { 2 - 4 } Type of area in 1966 (Rural is the omitted category) & & .452 & .422 \\
Urbanized & .434 & $(.498)$ & $(.494)$ \\
& $(.496)$ & .169 & .162 \\
Urban place & .165 & $(.375)$ & $(.368)$ \\
Instrumental Variables & $(.371)$ & 173.426 & 186.817 \\
Lottery Number & 181.566 & $(104.446)$ & $(102.888)$ \\
& $(103.689)$ & 184.389 & 178.315 \\
Lottery Ceiling & 180.697 & $(26.463)$ & $(32.065)$ \\
Proportion with at least one & 4 year accredited college in the neighborhood \\
Private College & .580 & .596 & .569 \\
Public College & $(.494)$ & $(.491)$ & $(.495)$ \\
& .481 & .494 & .473 \\
Total Number of & $(.500)$ & $(.500)$ & $(.499)$ \\
Observations & 2754 & 1080 & 1674 \\
\hline \hline
\end{tabular}


$\underline{\text { Table 2: Regression Results from Equation (1) }}{ }^{13}$

\begin{tabular}{|c|c|c|c|c|c|c|}
\hline & & \multicolumn{5}{|c|}{ Specifications } \\
\hline & & (A) & (B) & (C) & (D) & (E) \\
\hline \multicolumn{2}{|c|}{ Method of estimation } & IV & IV & OLS & OLS & IV \\
\hline \multicolumn{2}{|c|}{ Veteran is treated as } & endogenous & endogenous & exogenous & exogenous & endogenous \\
\hline \multicolumn{2}{|c|}{ Schooling is treated as } & endogenous & excluded & exogenous & excluded & exogenous \\
\hline \multirow{2}{*}{ Veteran } & $\begin{array}{l}\text { Coefficient: } \\
\quad \gamma\end{array}$ & $\begin{array}{l}-.374 * \\
(.222)\end{array}$ & $\begin{array}{l}-.172 \\
(.168)\end{array}$ & $\begin{array}{l}.019 \\
(.018)\end{array}$ & $\begin{array}{l}.019 \\
(.018)\end{array}$ & $\begin{array}{l}-.234 \\
(.165)\end{array}$ \\
\hline & $\begin{array}{l}\text { Effect: } \\
\qquad \delta=e^{\gamma}-1\end{array}$ & $\begin{array}{l}-.312 * * \\
(.153)\end{array}$ & $\begin{array}{l}-.158 \\
(.141)\end{array}$ & $\begin{array}{c}.019 \\
(.018)\end{array}$ & $\begin{array}{c}.019 \\
(.018)\end{array}$ & $\begin{array}{l}-.209 \\
(.131)\end{array}$ \\
\hline \multicolumn{2}{|l|}{ Schooling } & $\begin{array}{l}.161 * * \\
(.078)\end{array}$ & - & $\begin{array}{l}.049 * * * \\
(.003)\end{array}$ & - & $\begin{array}{c}.049 * * * \\
(.003)\end{array}$ \\
\hline \multicolumn{2}{|c|}{$\begin{array}{l}\text { Sargan-statistic } \\
\text { Test of over-identification }\end{array}$} & $\begin{array}{l}.044 \\
(.978)\end{array}$ & $\begin{array}{l}6.085 \\
(.108)\end{array}$ & - & - & $\begin{array}{l}3.084 \\
(.379)\end{array}$ \\
\hline \multirow{3}{*}{$\begin{array}{l}\text { Test of } \\
\text { Endogeneity }\end{array}$} & For Veteran & $\begin{array}{c}4.639 \\
(.0312)\end{array}$ & $\begin{array}{l}1.360 \\
(.244)\end{array}$ & - & - & $\begin{array}{l}2.573 \\
(.109)\end{array}$ \\
\hline & For Schooling & $\begin{array}{l}3.019 \\
(.082)\end{array}$ & - & - & - & - \\
\hline & $\begin{array}{l}\text { For Veteran } \\
\text { and Schooling }\end{array}$ & $\begin{array}{l}5.820 \\
(.055) \\
\end{array}$ & - & - & - & - \\
\hline \multirow{2}{*}{$\begin{array}{l}\text { Hausman Test } \\
\text { (use only } \\
\text { veteran and } \\
\text { schooling) }\end{array}$} & $\begin{array}{l}\text { Compare with } \\
\text { (C) }\end{array}$ & $\begin{array}{l}3.675 \\
(.159)\end{array}$ & - & - & - & $\begin{array}{l}2.385 \\
(.304)\end{array}$ \\
\hline & $\begin{array}{l}\text { Compare with } \\
\text { (E) }\end{array}$ & $\begin{array}{l}2.055 \\
(.358)\end{array}$ & - & - & - & - \\
\hline \multicolumn{2}{|c|}{$\begin{array}{l}\text { Anderson LM statistic } \\
\text { Test of under-identification }\end{array}$} & $\begin{array}{l}7.601 \\
(.055)\end{array}$ & $\begin{array}{l}33.65 \\
(.000)\end{array}$ & - & - & $\begin{array}{l}33.687 \\
(.000)\end{array}$ \\
\hline $\begin{array}{l}\text { Partial } R^{2} \\
\text { (Shea) }\end{array}$ & $\begin{array}{l}\text { Veteran } \\
\text { Schooling }\end{array}$ & $\begin{array}{l}.012 \\
.004\end{array}$ & $\begin{array}{c}.012 \\
-\end{array}$ & $\begin{array}{l}- \\
-\end{array}$ & $\begin{array}{l}- \\
-\end{array}$ & $\begin{array}{c}.012 \\
-\end{array}$ \\
\hline $\begin{array}{l}\text { F-stat for } \\
\text { instruments }\end{array}$ & $\begin{array}{l}\text { Veteran } \\
\text { Schooling }\end{array}$ & $\begin{array}{l}8.46 \\
2.53 \\
\end{array}$ & $\begin{array}{c}8.46 \\
- \\
\end{array}$ & $\begin{array}{l}- \\
-\end{array}$ & - & $\begin{array}{c}8.46 \\
- \\
\end{array}$ \\
\hline $\begin{array}{l}\text { Test of Weak } \\
\text { Identification: } \\
\text { Stock and } \\
\text { Yogo (2005) }\end{array}$ & $\begin{array}{l}\text { Cragg-Donald } \\
\text { Statistics } \\
\text { Bias of IV } \\
\text { relative to } \\
\text { OLS } \\
\text { Size of } 5 \% \\
\text { Wald-test }\end{array}$ & $\begin{array}{l}\text { more than } \\
30 \% \\
\text { more than } \\
25 \%\end{array}$ & $\begin{array}{c}\text { between } \\
10 \%-20 \% \\
\text { between } \\
20 \%-25 \%\end{array}$ & - & - & $\begin{array}{c}\text { between } \\
10 \%-20 \% \\
\text { between } \\
20 \%-25 \%\end{array}$ \\
\hline
\end{tabular}

\footnotetext{
${ }^{13}$ Results are based on 2754 observations. Rows corresponding to the coefficients contain the standard errors within parentheses. *, ** and *** represent significance at the 10 percent, 5 percent and 1 percent level respectively. Rows corresponding to the test of over and under identifications contain the p-values within parentheses.
} 
Table 2(a): Regression Results from Equation (1) ${ }^{14}$

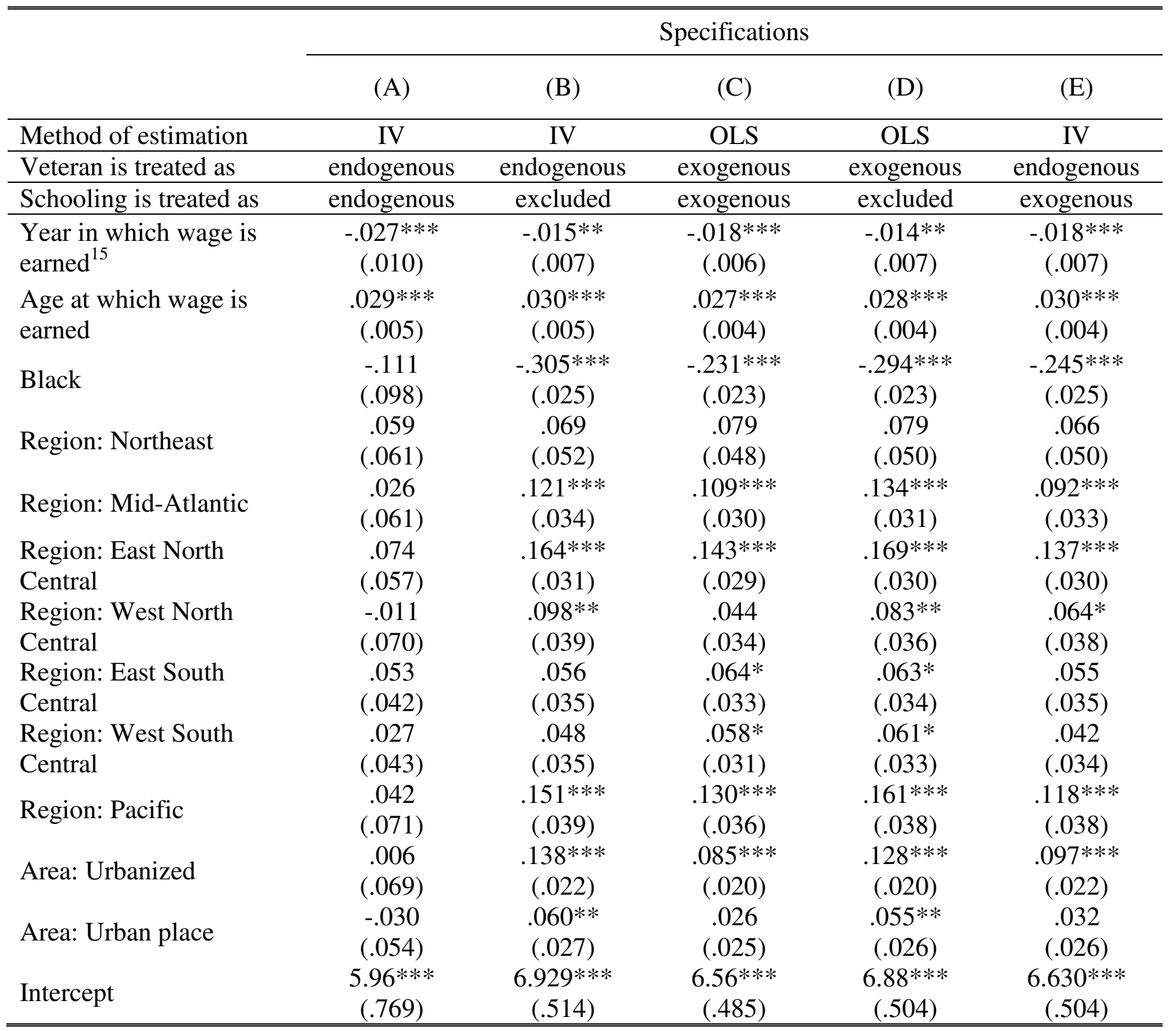

${ }^{14}$ Results are based on 2754 observations. Standard errors are reported within parentheses. *, ** and $* * *$ represent significance at the 10 percent, 5 percent and 1 percent level respectively.

${ }^{15}$ Had this been the variable of interest, once should use dummies to control for the years in which wage is earned to obtain practically meaningful coefficients. 
Table 3: Testing Exogeneity/Orthogonality restrictions in Equation (2)

\begin{tabular}{|c|c|c|c|c|c|}
\hline $\begin{array}{c}\text { Orthogonality of } \\
\text { instruments (tested) }\end{array}$ & $\begin{array}{l}4 \text { year public } \\
\text { college }\end{array}$ & $\begin{array}{l}4 \text { year private } \\
\text { college }\end{array}$ & $\begin{array}{l}4 \text { year public } \\
\text { college }\end{array}$ & $\begin{array}{l}4 \text { year private } \\
\text { college }\end{array}$ & $\begin{array}{l}4 \text { year public } \\
4 \text { year private }\end{array}$ \\
\hline C-statistic & .041 & .043 & .001 & .003 & .044 \\
\hline (p-value) & $(.839)$ & $(.836)$ & $(.979)$ & $(.957)$ & $(.978)$ \\
\hline Sargan-statistic & .041 & .043 & .044 & .044 & .044 \\
\hline (p-value) & $(.839)$ & $(.836)$ & $(.978)$ & $(.978)$ & $(.978)$ \\
\hline $\begin{array}{l}\text { Instruments used in } \\
\text { the model }\end{array}$ & $\begin{array}{l}\text { 1) } 4 \text { year public } \\
\text { 2) Lottery number } \\
\text { 3) Ceiling in Lottery }\end{array}$ & $\begin{array}{l}\text { 1) } 4 \text { year private } \\
\text { 2) Lottery number } \\
\text { 3) Ceiling in Lottery }\end{array}$ & $\begin{array}{l}\text { 1) } 4 \text { year public } \\
\text { 2) } 4 \text { year private } \\
\text { 3) Lottery number } \\
\text { 4) Ceiling in Lottery }\end{array}$ & $\begin{array}{l}\text { 1) } 4 \text { year public } \\
\text { 2) } 4 \text { year private } \\
\text { 2) Lottery number } \\
\text { 3) Ceiling in Lottery }\end{array}$ & $\begin{array}{l}\text { 1) } 4 \text { year public } \\
\text { 2) } 4 \text { year private } \\
\text { 3) Lottery number } \\
\text { 4) Ceiling in Lottery }\end{array}$ \\
\hline
\end{tabular}


Figure 1: $95 \%$ Confidence Regions based on each test is the region below the horizontal red line (plotted are (subset test statistic - critical values))
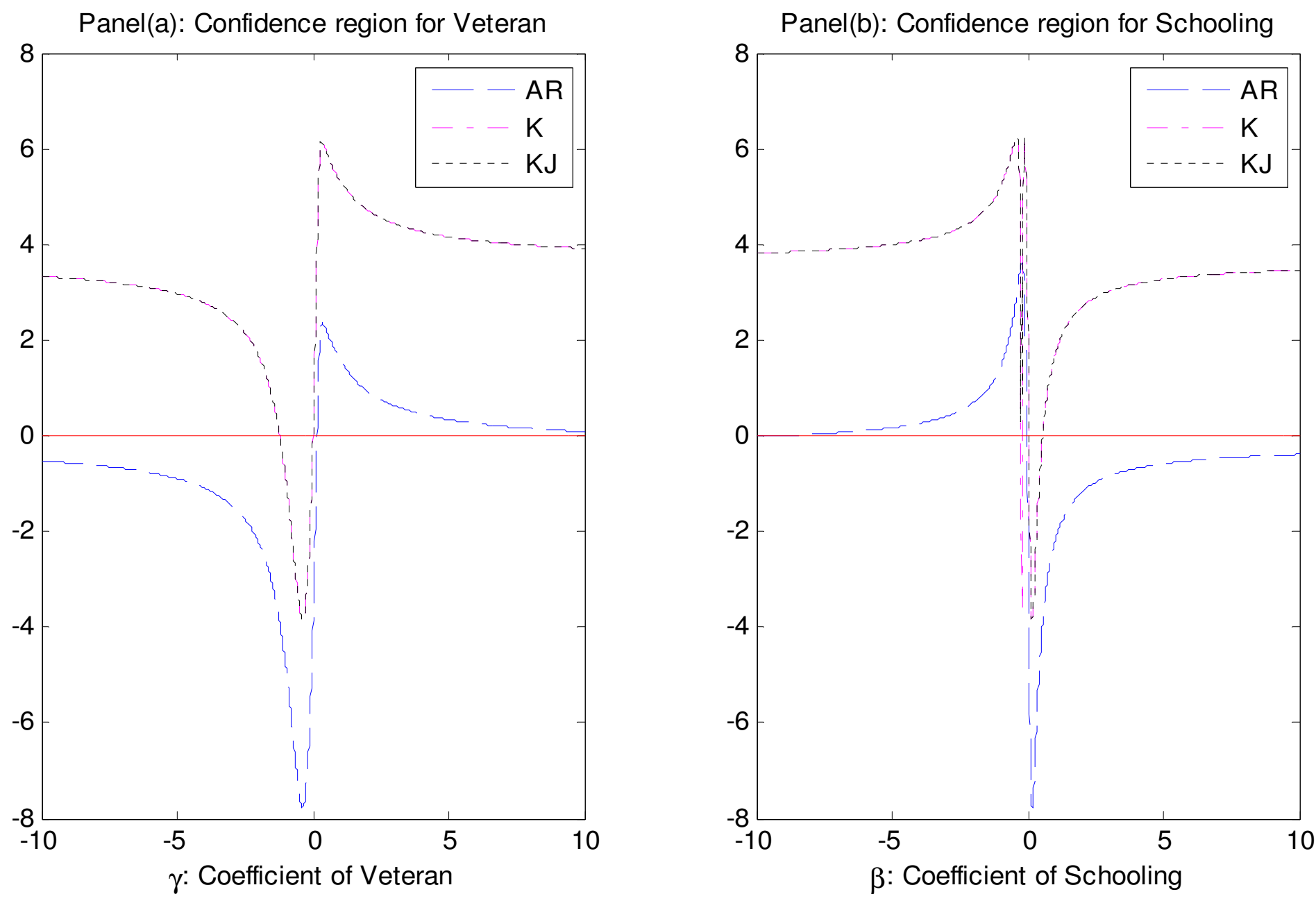
Figure 1(b): $95 \%$ Confidence Regions based on each test is the region below the horizontal red line (plotted are (subset test statistic - critical values))

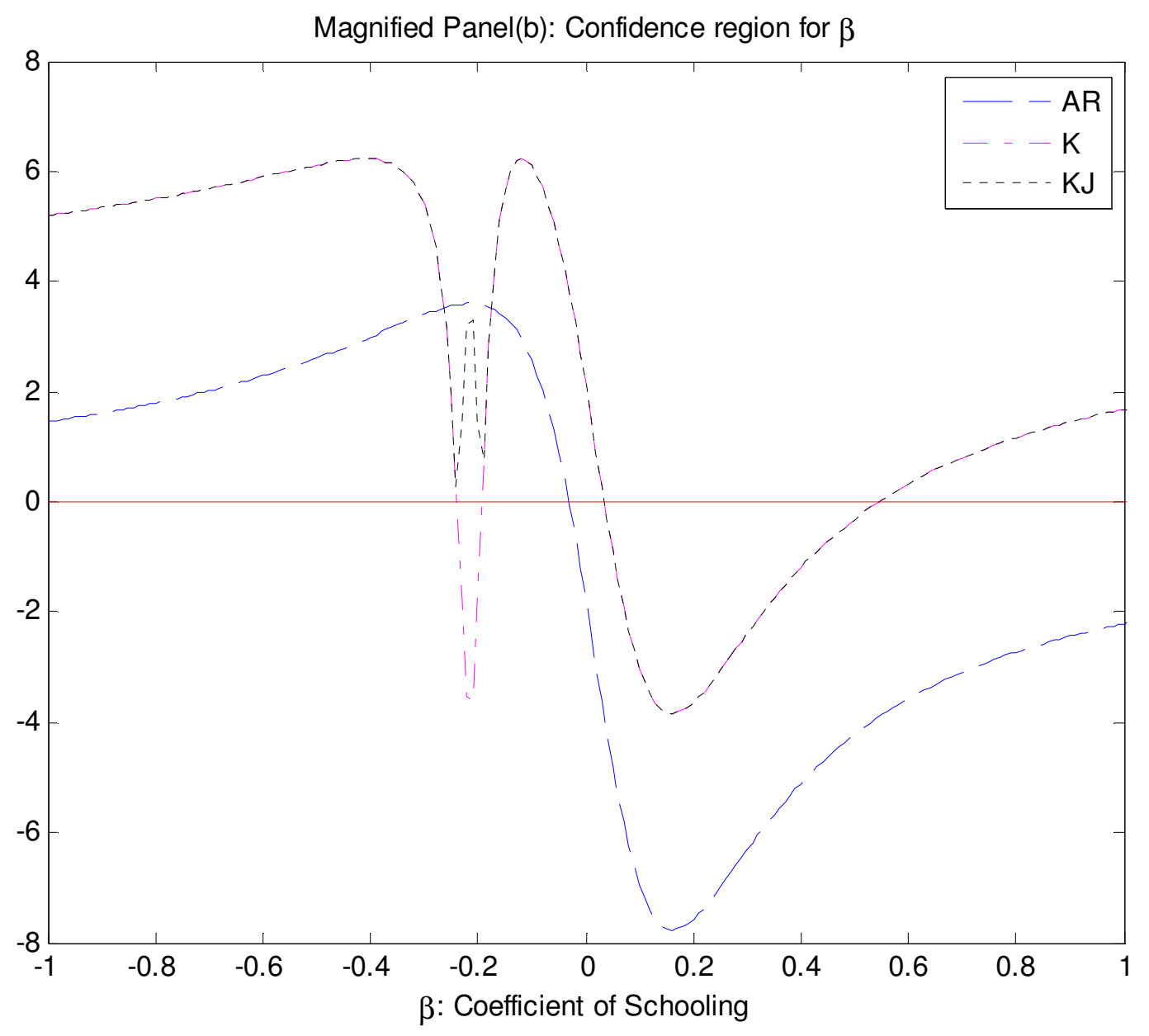

